\title{
RESPONSABILIDADE COMPARTILHADA SOBRE OS RESÍDUOS SÓLIDOS E EDUCAÇÃO AMBIENTAL NO CONTEXTO URBANO AMAZÔNICO
}

\author{
Paulo Vitor dos Santos Gonçalves ${ }^{1}$ \\ Paulo Amador Tavares ${ }^{2}$ \\ Fernanda Neves Ferreira ${ }^{3}$ \\ Vítor Abner Borges Dutra ${ }^{4}$ \\ Norma Ely Santos Beltrão ${ }^{5}$ \\ Hélio Raymundo Ferreira Filho ${ }^{6}$ \\ Hebe Morganne Campos Ribeiro ${ }^{7}$
}

Resumo: No arcabouço da Política Nacional de Resíduos Sólidos (PNRS), está previsto o princípio da responsabilidade compartilhada (RC). Propõe-se, neste trabalho, abordar a responsabilidade dos indivíduos na gestão compartilhada e como esta pode ser acentuada através da Educação Ambiental. Especificamente, o objetivo deste artigo foi investigar o contexto da $\mathrm{RC}$ dos moradores de uma bacia hidrográfica urbana na cidade de Belém, Pará, relacionando esta percepção com as características socioeconômicas desses indivíduos. Concluiu-se que a inserção de temáticas relacionadas ao meio ambiente e sustentabilidade na educação formal poderia tornar a população mais proativa dentro do cenário da gestão de resíduos sólidos.

Palavras-chave: Gerenciamento de Resíduos Sólidos; Conscientização Ambiental; Sustentabilidade Urbana; Práticas Sustentáveis; Responsabilidade Compartilhada.

\footnotetext{
${ }^{1}$ Universidade do Estado do Pará. E-mail: paulogoncalves@uepa.br

2 Universidade do Estado do Pará. E-mail: paulo.tavares@uepa.br

3 Universidade do Estado do Pará. E-mail: nanda_fnf@yahoo.com.br

${ }^{4}$ Universidade do Estado do Pará. E-mail: abner_dutra_@hotmail.com

5 Universidade do Estado do Pará. E-mail: normaely@uepa.br

6 Universidade do Estado do Pará. E-mail: helio.ferreira@uepa.br

7 Universidade do Estado do Pará. E-mail: hebemcr@gmail.com
} 


\section{Introdução}

A Educação Ambiental está relacionada a qualquer forma de conscientização dos indivíduos às questões que envolvam as problemáticas ambientais (REIGOTA, 2017; OLIVEIRA, 2016). Para tanto, há diferentes abordagens que visam alcançar o objetivo principal de conscientizar o indivíduo, dentre as quais têm-se a Educação Ambiental formal e não-formal (ROSA; CARNIATTO; COELHO, 2017).

De acordo com a Lei o․ 9.795 de 27 de abril de 1999, que institui a Política Nacional de Educação Ambiental (PNEA), entende-se por Educação Ambiental (EA) formal aquela desenvolvida no âmbito escolar, dentro dos currículos das instituições de ensino. Por outro lado, a EA não-formal aborda ações e práticas educativas voltadas à sensibilização da coletividade sobre as questões ambientais e à sua organização e participação na defesa da qualidade do meio ambiente (BRASIL, 1999).

Nesse cenário de busca pela conscientização ambiental, a Lei ํㅡ. 12.305 de 2 de agosto de 2010 que promulgou a Política Nacional de Resíduos Sólidos (PNRS), aponta a EA enquanto instrumento que efetiva o princípio da Responsabilidade Compartilhada (RC) pelo ciclo de vida dos produtos (BRASIL, 2010). Este princípio prevê a participação de todos os membros da sociedade na correta gestão e disposição final dos resíduos sólidos (SANTOS, 2015). De tal efeito, vislumbra-se a abordagem da conscientização ambiental relacionada com os instrumentos previstos na PNRS.

Maiello, Britto e Valle (2018), ao avaliarem a implantação da PNRS concluíram que muitos municípios e estados ainda estão em déficit na adequação aos objetivos da política. É nessa perspectiva que o aumento da preocupação dos indivíduos com a $\mathrm{RC}$ pode colaborar com a redução da produção de resíduos, através do consumo e uso sustentável, da adequada destinação final desses resíduos e, consequentemente, do alcance dos demais objetivos tanto da PNEA quanto da PNRS.

Assim, o desenvolvimento de pesquisas científicas e trabalhos de extensão como forma de aprimoramento de técnicas formais e não-formais de EA contribuem para melhorar o conhecimento dos indivíduos sobre os seus deveres e responsabilidades relacionados aos RS (MORAR; BUCUR, 2017; RADA et al., 2016). Tremblay (2013) destaca que a correta comunicação dos resultados das pesquisas e das informações é relevante para a gestão de RS municipais.

Coelho, Haonat e Arantes (2017) e Santos (2015) em abordagens teóricas sobre a PNRS, apresentaram a EA como a principal alternativa para a conscientização ambiental na temática de RS. Nesse contexto, ressalta-se que os desafios para incorporação dos conceitos de RC são encontrados em todos os países, sejam desenvolvidos ou em desenvolvimento (SALTER; VEVILLE; LONGNECKER, 2011). Estes mesmos autores concluíram que os habitantes 
da Austrália enfrentam desafios quanto à inserção da abordagem da RC no cenário da educação básica.

Haworth (2016), em estudo de caráter exploratório sobre sua carreira dentro da gestão e infraestrutura de RS em áreas urbanas, destacou a importância da educação formal no processo de aprendizado e conscientização dos indivíduos. O mesmo autor salientou a importância da inserção de técnicas de aprendizado em EA com a temática de RS desde o ensino básico, além disso, concluiu que as crianças têm o potencial de levar o aprendizado de sala de aula para dentro de casa, acarretando na conscientização de todos os indivíduos dentro do núcleo familiar.

Nesta mesma perspectiva, Tavares, Beltrão e Pimenta (2017) abordaram a inserção da EA dentro do ensino básico brasileiro. Em revisão de literatura sobre estudos de casos publicados na Revista Brasileira de Educação Ambiental, os autores puderam encontrar diversas temáticas, como o uso consciente de água e energia e principalmente a correta destinação de RS, que foi considerada em $50 \%$ dos estudos analisados nessa pesquisa.

Ainda na perspectiva de EA em cenários de educação básica e primária, Zorpas, Voukkali e Loizia (2017) fizeram um levantamento sobre o desenvolvimento de programas voltados às crianças para a prevenir a geração de RS. Seguindo o pensamento de Haworth (2016), os autores puderam reforçar a ideia da estruturação da base educacional como forma de compor uma conscientização geral sobre a compreensão das responsabilidades de cada indivíduo.

No estudo realizado em Maine, Estados Unidos da América, McGreavy et al. (2018) abordaram a necessidade da inserção das comunidades na participação da gestão ambiental, haja vista que estas vivem na zona costeira do estado. Os autores afirmaram a premência do aprimoramento da comunicação entre estado e sociedade civil, de forma a conscientizar sobre a gestão e responsabilidade que cada indivíduo deve possuir, caracterizando um método não-formal de EA na abordagem de RC. Em outro trabalho, Ghisolfi et al. (2017) destacaram a necessidade da inserção social dos catadores na gestão de RS, ao salientar que, devido ao mau funcionamento do setor formal (composto por órgãos de limpeza pública, cooperativas, recicladores e associações), esses indivíduos atuariam como importantes atores no cenário da gestão de resíduos municipais brasileiros. Considerando que grande parte dos RS são coletados por intermediários ou catadores, trabalhar a EA com essa categoria poderia trazer melhoria na qualidade de vida de seus integrantes, além de contribuir para o aprimoramento das gestões municipais de RS.

Nessa perspectiva, verificou-se a necessidade de estudos que abordem a temática de RC dentro de um cenário de EA, seja ela formal ou não-formal. Nos principais municípios do Brasil ainda se percebe a insuficiência de serviços públicos de RS (MAIELLO; BRITTO; VALLE, 2018), a falta de compreensão 
dos habitantes quanto ao consumo consciente e à disposição adequada de seus resíduos e a carência de incentivos às iniciativas verdes.

Em vista do exposto, o presente estudo objetivou investigar o contexto da $\mathrm{RC}$ de moradores em uma bacia hidrográfica urbana na cidade de Belém, Pará, além de relacionar esta percepção com variáveis socioeconômicas desses indivíduos. Por meio disso, analisou-se também a possibilidade da aplicação de métodos de EA formal e não-formal para melhoria do cenário de RS nessa região.

\section{A responsabilidade compartilhada na legislação ambiental brasileira}

Alega-se que a RC, como um princípio previsto na Lei da PNRS, é derivada da orientação do princípio do poluidor-pagador (MOREIRA et al., 2016). Este princípio foi reconhecido pela Organização para Cooperação e Desenvolvimento Econômico (OCDE) na década de 1970, com o objetivo de repassar ao causador do dano ambiental os custos das medidas preventivas e controle da poluição, estimulando-o ao uso racional dos recursos ambientais escassos e, assim, evitar distorções no comércio e investimentos internacionais (OECD, 1992).

Esse princípio surgiu a partir da percepção de que os custos privados do poluidor estavam sendo transferidos à sociedade (GORDILHO; PIMENTAL, 2018). Apesar de ter tido uma orientação econômica no início, este princípio também retrata um componente de justiça pela ideia de que um indivíduo não deve lucrar ao custo da sociedade (TABOADA, 2005).

Pelo fato de os bens ambientais serem recursos comuns, ou seja, bens rivais e não-excludentes, as externalidades surgem devido à ausência de preço representativo no mercado que ocasiona a alocação ineficiente desses recursos. Externalidades são, portanto, os impactos no bem-estar de terceiros, que não participam da ação que os gerou e não recebem qualquer compensação por isso. As externalidades são negativas quando os impactos são adversos aos terceiros, por outro lado, são positivas quando trazem benefícios. A presença de externalidades torna o equilíbrio do mercado ineficiente, pois não são refletidas nos preços, revelando-se como falhas de mercado (MANKIW, 2001).

Nesse sentido, os impactos gerados pela destinação inadequada dos RS são externalidades negativas. Consequentemente, a destinação ambientalmente adequada é considerada uma medida importante no controle da poluição atrelada ao princípio do poluidor-pagador (MOREIRA et al., 2016). Contudo, para que as ações de destinação adequada sejam efetivas, é imprescindível, previamente, estimular no consumidor a adoção de um modelo circular de consumo, transformando a cultura do descarte de modo a incentivar que os RS sejam vistos não mais como um fim, e sim como um subproduto. A atuação sobre o consumidor é essencial, pois ele é o principal agente dentro da 
lógica de mercado de consumo, descarte e reposição de produtos (PETHECHUST; CASIMIRO, 2016).

Para que ocorra a internalização dos custos do consumo, a RC é vista como um princípio indutor de redução da geração de resíduos que enseja mudanças comportamentais que atingem desde o fabricante até o consumidor (PETHECHUST; CASIMIRO, 2016). Partindo da premissa de que a responsabilidade consiste na consciência ambiental tanto em escala local quanto global, esse princípio da Lei da PNRS é intimamente dependente dos processos de EA, sensibilização e mobilização social (BARCIOTTE; SACCARO JÚNIOR, 2012).

\section{Metodologia}

\section{Característica da pesquisa}

A pesquisa foi aplicada do ponto de vista da sua natureza, pois buscou gerar conhecimento sobre a percepção da EA dos moradores das proximidades da bacia hidrográfica do Tamandaré. Quanto aos seus objetivos definiu-se como pesquisa descritiva, uma vez que os fatos foram classificados, explicados e interpretados sem intervenção nos dados (PRODANOV; FREITAS, 2013).

O procedimento para a realização do estudo consistiu de pesquisa bibliográfica e levantamento do tipo survey, devido à utilização da literatura existente sobre EA e a entrevista direta dos moradores da área de estudo para coletar informações concernentes aos seus dados socioeconômicos e ambientais (SEVERINO, 2017; PRODANOV; FREITAS, 2013).

\section{Área de estudo}

Essa pesquisa foi realizada na bacia hidrográfica urbana do Tamandaré, em Belém, Pará. De acordo com o anuário estatístico do município, a área de estudo encontra-se dentro do Distrito Administrativo de Belém, especificamente entre os bairros Batista Campos, Campina e Cidade Velha, sendo sua população estimada em 19.136, 6.156 e 12.128 habitantes, respectivamente (BELÉM, 2012). A renda média por família no município é aproximadamente 3,5 salários mínimos, a taxa de escolarização é $96,1 \%$ para pessoas de 6 até 14 anos e o índice de desenvolvimento humano municipal é 0.746 (IBGE, 2018).

A Figura 1 ilustra a localização geográfica da bacia hidrográfica do Tamandaré dentro da malha urbana do município de Belém. 


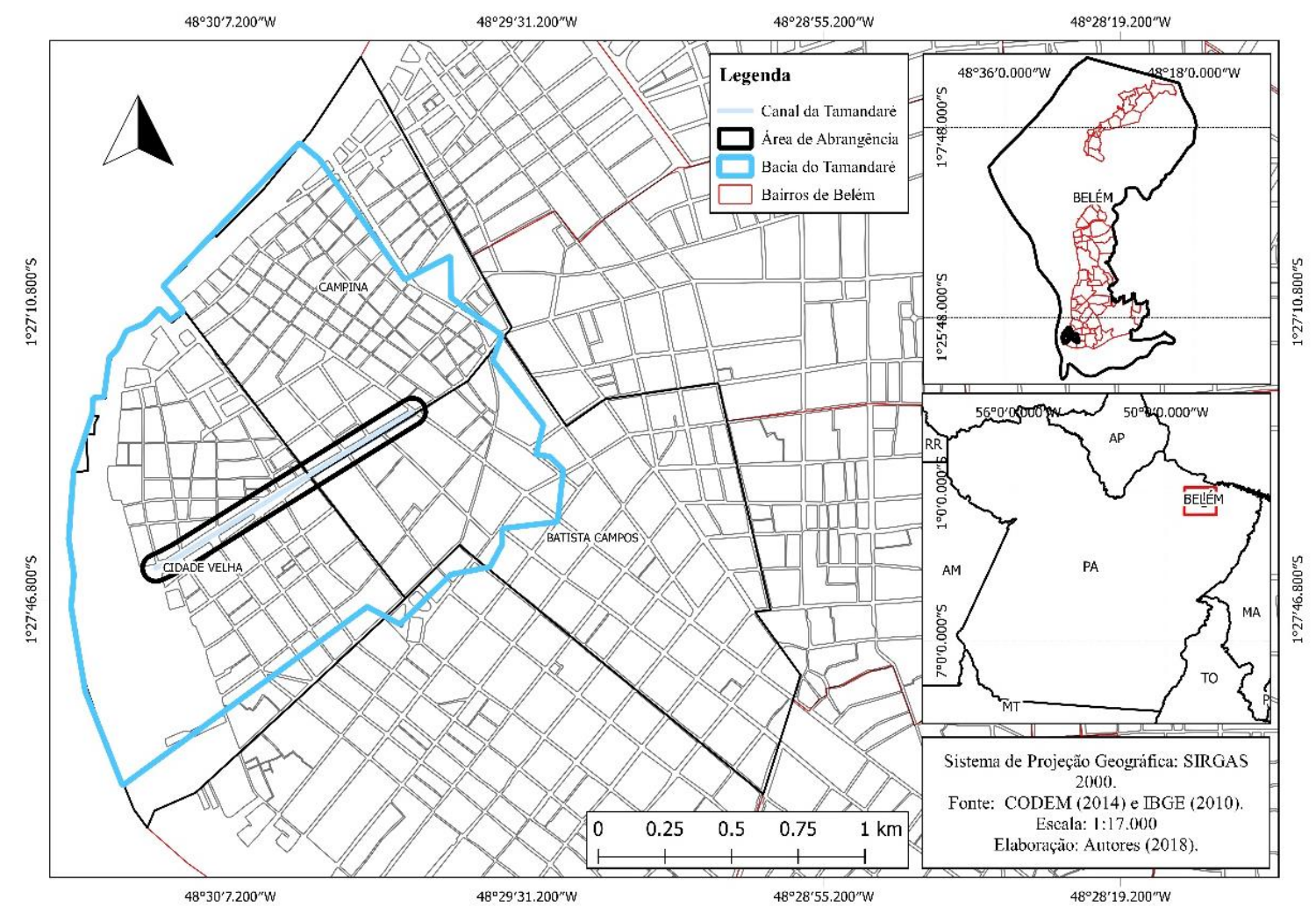

Figura 1: Mapa de localização da bacia hidrográfica do Tamandaré.

Fonte: Autores (2018)

\section{Coleta e análise de dados}

Para o cálculo amostral estimou-se a população do bairro da Cidade Velha que reside em uma área delimitada próxima ao canal da Tamandaré. Esta área circunda as margens do canal e foi ilustrada por um polígono limitado pelo comprimento do canal (1.270 metros) e uma largura correspondente a 100 metros, totalizando $0,12 \mathrm{~km}^{2}$ de área. A população foi determinada por meio do produto da densidade populacional do bairro pela área do entorno do canal, resultando em aproximadamente 158 habitantes na área delimitada pelo polígono.

A amostra foi calculada conforme a equação utilizada por Dutra et al. (2018), aplicada à uma população finita, situação semelhante ao considerado neste estudo. Foi admitido um erro amostral de $10 \%$, justificado pelo fato do canal da Tamandaré apresentar muitos pontos comerciais, o que afetou a interrogação de indivíduos que fossem efetivamente moradores locais. Além disso, a percepção ambiental dessas pessoas alheias à área de estudo comprometeria a análise estatística realizada, reduzindo a efetividade do objetivo proposto por este artigo.

Desta forma, foram aplicados e preenchidos 60 questionários na área delimitada pelos autores nas proximidades do canal da Tamandaré, durante o mês de junho de 2018. Estes questionários foram adaptados dos modelos 
apresentados em outros trabalhos (SOUSA et al., 2016; SILVA et al., 2014) e abordaram questões sobre aspectos socioeconômicos e o conceito de RC, preconizada no art. 3으, inc. VXII da Lei da PNRS (BRASIL, 2010).

Foi utilizado o software $\mathrm{R}$ (versão 3.5.0) para a realização do teste quiquadrado $\left(x^{2}\right)$. $O$ teste foi empregado para avaliar a relação entre o nível de educação formal dos entrevistados com sua percepção sobre o conceito de RC e satisfação com a gestão de RS, com nível de significância de 0,05. O quiquadrado é aplicado para testar 2 variáveis categóricas em que a distribuição de uma variável muda de acordo com os valores da outra, além de evidenciar se há associação ou não entre elas (KOLETSI; PANDIS, 2016; PANDIS, 2016).

\section{Resultados e discussão}

A Tabela 1 apresenta o resumo estatístico da associação realizada pelo teste $\chi^{2}$ entre as variáveis "nível de educação formal", "gênero", "renda" e "idade" com a variável "RC" a qual perguntava aos entrevistados se possuíam entendimento sobre este princípio abordado na Lei da PNRS.

Tabela 1: Associação das variáveis pelo Teste Qui-Quadrado.

Dados socioeconômicos e Responsabilidade Compartilhada (Teste Qui-Quadrado)

\begin{tabular}{lcc}
\hline Variáveis & $x^{2}$ & $p$ \\
\hline Nível de educação formal & 5,57 & $0,022^{*}$ \\
Gênero & 0,136 & 0,713 \\
Renda & 4,313 & 0,115 \\
Idade & 0,193 & 0,979 \\
\hline
\end{tabular}

*Associações estatisticamente significativas entre os grupos $(p<0,05)$.

Fonte: Autoria própria, 2018.

Verifica-se que, dentre as variáveis avaliadas no estudo, o nível de educação formal obteve relação significativa $(p=0,022)$ quando associado com o entendimento sobre RC. Em contrapartida, as demais variáveis (gênero, renda e idade) apresentaram valores de relação não significativos, sugerindo que fatores como gênero, idade ou a renda declarada dos entrevistados não influenciam na sua percepção de conceitos relacionados ao meio ambiente, como a RC.

A influência na percepção de conceitos relacionados com a sustentabilidade e o meio ambiente é vista no estudo realizado por lbáñezFóres et al. (2018), que avaliaram a participação de um grupo de indivíduos no programa de coleta seletiva na cidade de João Pessoa, Paraíba. O estudo verificou que não há relação significativa da participação de pessoas com as 
variáveis idade, gênero e renda mensal na separação dos RS para a coleta seletiva municipal.

Os autores supracitados destacam ainda que investir na otimização e disseminação das campanhas de conscientização com atividades que envolvam os processos educativos dos cidadãos de João Pessoa são aspectos capazes de melhorar a relação da participação na coleta seletiva. Contribuir no processo de coleta seletiva separando os resíduos da maneira adequada demonstra o nível de conhecimento perante o conceito de $\mathrm{RC}$ sobre os $\mathrm{RS}$, afirmando a importância do nível de educação da população.

O nível de educação reflete diretamente sobre o entendimento dos indivíduos quanto ao conceito de RC, viabilizando a participação ativa da população na gestão integrada dos RS (REIS; FRIEDE; LOPES, 2017). Estes autores enfatizaram que a população possui papel fundamental na correta destinação dos resíduos produzidos, sendo agente fiscalizador das ações sustentáveis do gerenciamento urbano quanto às questões ambientais relacionadas aos RS, além de tornar o processo de reciclagem economicamente mais viável, por conta de atenuar os processos de triagem dos materiais coletados.

Mayer (2013), ao estudar a relação entre a educação e o meio ambiente, demonstrou a existência da relação do nível de educação de um grupo populacional com sua percepção ambiental, tal como ocorre na associação entre o nível de educação formal e a RC, abordados neste artigo. Logo, aumentar o nível da educação formal dos moradores do canal da Tamandaré permitiria melhor entendimento sobre esse conceito abordado na Lei da PNRS e os benefícios ambientais atrelados a ele.

Para Gasques et al. (2016), a EA é tida como solução para as necessidades de ensino sobre questões ambientais, pois envolvem preservação e conscientização, temas estes que não são abordados satisfatoriamente pela educação formal. Nesse sentido, a elaboração de programas e ações de EA influenciariam positivamente no nível de educação formal e na RC perante a gestão dos RS, conforme destaca a Lei da PNRS (BRASIL, 2010).

Kondrat e Maciel (2013) elaboraram um trabalho sobre a EA para a educação básica, e a destacaram como facilitadora de um processo educativo mais orientado para a formação da cidadania. Isso fomenta ainda o compromisso do ser humano com o presente e o futuro do meio ambiente, por meio de uma abordagem que promove discussões sobre questões ambientais e transformações do conhecimento.

Dessa forma, práticas de EA podem otimizar a compreensão do conceito de RC na área de estudo, fortalecendo a educação formal e o compromisso da população em atuar na defesa do meio ambiente equilibrado, essencial à sadia qualidade de vida, preservando-o para atuais e futuras gerações através da conscientização em todos os níveis da sociedade e de ensino, conforme 
destaca o Art. 225 da Constituição Federal (BRASIL, 1988). A literatura acrescenta ainda que os conhecimentos concernentes à EA podem ser transferidos entre as gerações e induzir nas mudanças comportamentais de adultos e crianças (DAMERELL; HOWE; MILNER-GULLAND, 2013).

Moura et al. (2014) afirmaram ser imprescindível a utilização de práticas de EA nos diferentes níveis de educação formal, tanto na rede pública quanto na rede privada de ensino, para que ocorra a conscientização e crescimento da percepção ambiental de jovens e adultos preocupados com as questões relacionadas ao meio ambiente. Essas práticas atenuam as problemáticas relacionadas à disposição irregular dos RS no canal da Tamandaré.

Dutra et al. (2018) apontaram a pressão causada pela ineficiência da coleta de RS no canal da Tamandaré e diversos problemas ambientais ligados a este fator, como forte odor, proliferação de vetores e alagamentos. Os autores destacaram a promoção de atividades de EA junto à população para alterar o patamar do cenário encontrado, tornando-o menos prejudicial aos residentes da área e a este recurso hídrico urbanizado.

Além disso, reverbera-se o conceito de RC perante o ciclo de vida dos produtos no Plano de Gerenciamento Integrado de Resíduos Sólidos (PGRS) do município de Belém (Lei o․ . 8899, de 26 de dezembro de 2011). No entanto, pouco se faz na região do canal da Tamandaré a respeito da disposição irregular dos RS por parte de alguns moradores (DUTRA et al., 2018).

A disseminação da EA junto às práticas de educação formal, como modo de enraizar o conceito de RC e garantir a melhor gestão dos RS por estes moradores locais, deve ser vista como resposta fundamental para a problemática abordada. Essa resposta pode ser elaborada de maneira não estrutural, por meio da formulação de cartilhas e realização de palestras esclarecedoras sobre os malefícios à saúde humana e ao meio ambiente atribuídos ao dispêndio irregular dos RS.

As medidas de educação são consideradas por Costa e Costa (2011) como instrumentos na construção da consciência ambiental, em que todos os processos para o seu desenvolvimento e aprimoramento na sociedade nos mais diferentes níveis têm sido significativos na formação da consciência sensível às questões ambientais e às medidas de mensuração dos impactos em diferentes escalas. Dito isso, depreende-se que investir em propostas de melhoria da educação formal e ambiental das pessoas em áreas como o canal da Tamandaré contribuiria para a preservação e manutenção da qualidade ambiental, principalmente quanto à disposição dos RS, problema frequente do local estudado.

Ademais, a gestão pública, como fomentadora da propagação de campanhas educativas, deve conduzir aspectos práticos para a população participante ao abordar sobre a EA para RS perante a ótica da RC. Deve-se vincular as informações oferecidas às modificações efetivas no comportamento, como por exemplo: a importância da coleta seletiva e a 
distribuição de postos de entrega voluntária de materiais recicláveis para os moradores locais e demais transeuntes (LEITE; BELCHIOR, 2014).

Murakami et al. (2015) ao avaliarem as políticas públicas que fomentam a reciclagem no Brasil concluíram que a gestão governamental deve focar nos processos educativos, pois melhoram a consciência ambiental da população, assim como dos catadores de resíduos, atores fundamentais no processo de reciclagem e reutilização do lixo no cenário brasileiro. Portanto, para que os residentes do canal da Tamandaré internalizem a $\mathrm{RC}$ e agucem sua percepção ambiental, é necessário um governo participativo e preocupado em educar e formar cidadãos mais conscientes.

Silva (2018), ao propor um modelo dinâmico de avaliação de políticas públicas para a cidade de Curitiba, Paraná (uma das capitais brasileiras mais importantes em termos de gestão de RS), destacou que investimentos em políticas de EA no município possibilitam aumentar a quantidade de material destinado à coleta seletiva. A reciclagem é, portanto, uma alternativa de investimento para reduzir os impactos ambientais e econômicos provenientes dos RS e da disposição destes em aterros sanitários.

Assim, evidencia-se a necessidade da gestão municipal de Belém em investir apropriadamente no setor educacional a fim de promover o aumento da consciência e percepção ambiental dos indivíduos, de modo a reduzir os impactos da disposição inadequada dos RS no canal da Tamandaré e demais áreas da cidade. Essa afirmativa justifica-se também devido à relação significativa, identificada neste estudo, entre o nível educacional dos entrevistados e seu entendimento sobre RC, princípio essencial para gestão eficiente dos RS (BRASIL, 2010).

\section{Considerações finais}

A exploração dos dados encontrados com a aplicação dos questionários mostrou que não houve relação significativa entre o conhecimento sobre a temática de $\mathrm{RC}$ com a renda, gênero e idade dos habitantes da região hidrográfica urbana estudada. A única variável analisada que apresentou significativa relação com a temática foi o nível de educação formal dos entrevistados.

A discussão com a literatura elucidou que a inserção de assuntos relacionados ao meio ambiente e sustentabilidade por meio da educação deve tornar a população mais ativa dentro do cenário da gestão de RS municipais. A literatura destacou também que os cidadãos e a gestão pública municipal são igualmente responsáveis pelo gerenciamento dos $\mathrm{RS}$, caracterizando a RC.

Foi possível, portanto, evidenciar a ineficiência no processo de gerenciamento de RS na região do canal da Tamandaré e que isso pode ser solucionado, em parte, com a inserção da conscientização ambiental por meio do fomento da EA, seja ela formal ou não-formal. Algumas soluções propostas 
pela literatura foram a promoção de campanhas de conscientização e a maior inclusão de temáticas relacionadas à $\mathrm{RC}$ dentro do ensino formal municipal.

\section{Referências}

BARCIOTTE, M. L.; SACCARO JUNIOR, N. L. Sensibilização e mobilização dentro da Política Nacional de Resíduos Sólidos: desafios e oportunidades da Educação Ambiental. Brasília: IPEA, 2012. Disponível em: $<$ http://repositorio.ipea.gov.br/bitstream/11058/1108/1/TD 1755.pdf >. Acesso em: 30 ago. 2018.

BELÉM (Município). Anuário Estatístico do Município de Belém 2011. Belém: Secretaria Municipal de Coordenação Geral do Planejamento e Gestão, 2012.

BELÉM (Município). Lei Ordinária no 8899, de 26 de dezembro de 2011. Institui o Plano de Gerenciamento Integrado de Resíduos Sólidos do Município de Belém - PGRS e dá outras providências, 2011.

BRASIL. Constituição da República Federativa do Brasil de 1988, 05 de outubro de 1988. Brasília-DF, 1988.

BRASIL. Lei no 12.305, de 2 de agosto de 2010. Institui a Política Nacional de Resíduos Sólidos; altera a Lei no 9.605, de 12 de fevereiro de 1998; e dá outras providências. Brasília-DF, 2010.

BRASIL. Lei no 9.795, de 27 de abril de 1999. Dispõe sobre a Educação Ambiental, institui a Política Nacional de Educação Ambiental e dá outras providências. Brasília-DF, 1999.

COELHO, A.; HAONAT, Â. I.; ARANTES, E. B. A Política Nacional de Resíduos Sólidos (PNRS) brasileira frente a tutela constitucional quanto ao tratamento do lixo eletrônico e sua repercussão humanística. Espacios, v. 38, n. 41, p. 29, 2017.

COSTA, C. A. DA; COSTA, F. G. A educação como instrumento na construção da consciência ambiental. Nucleus, v. 8, n. 2, p. 421-440, 28 out. 2011.

DAMERELL, P; HOWE, C; MILNER-GULLAND, E J. Child-orientated environmental education influences adult knowledge and household behaviour. Environmental Research Letters, v. 8, n. 1, p. 015016, 2013.

DUTRA, V. A. B.; GONÇALVES, P. V. S.; CAMPOS, M. V. A.; TAVARES, P. A.; BELTRÃ̃O, N. E. S. Saneamento Em Áreas Urbanas Na Amazônia: Aplicação Do Sistema De Indicadores PEIR. Revista Gestão \& Sustentabilidade Ambiental, v. 7, n. 2, p. 652-671, abr./jun. 2018.

GASQUES, A. C. F.; OKAWA, C. M. P.; SANTOS, J. D.; GASQUES, E. G. F.; DELABIO, F. Educação Ambiental: esudo de caso em dois colégios estaduais da cidade Sarandi (PR). Revista Brasileira de Educação Ambiental (RevBEA), v. 11, n. 5, p. 123-138, 2016. 
GHISOLFI, V.; CHAVES, G. L. D.; SIMAN, R. R.; XAVIER, L. H. System dynamics applied to closed loop supply chains of desktops and laptops in Brazil: A perspective for social inclusion of waste pickers. Waste Management, v. 60, p. 14-31, 2017.

GORDILHO, H. J. S.; PIMENTA, P. R. L. Fins do princípio do poluidor-pagador. Revista Brasileira de Direito, Passo Fundo, v. 14, n. 1, p. 361-379, jan./abr., 2018.

HAWORTH, J. Environmental education in public schools leads to improvements in solid waste management. Waste Management \& Research, v. 34, n. 11, p. 1097-1098, 2016.

IBÁÑEZ-FORÉS, V. et al. Influence of implementing selective collection on municipal waste management systems in developing countries: A Brazilian case study. Resources, Conservation and Recycling, v. 134, p. 100-111, jul. 2018.

IBGE - Instituto Brasileiro de Geografia e Estatística. Panorama do Município de Belém. 2018. Disponível em: <https://cidades.ibge.gov.br/brasil/pa/belem/ panorama>. Acesso em: 01 set. 2018.

KOLETSI, D.; PANDIS, N. The chi-square test for trend. American Journal of Orthodontics and Dentofacial Orthopedics, v. 150, n. 6, p. 1066-1067, 2016.

KONDRAT, H.; MACIEL, M. D. Educação Ambiental para a escola básica: contribuições para o desenvolvimento da cidadania e da sustentabilidade. Revista Brasileira de Educação, v. 18, n. 55, 2013.

LEITE, J. R. M.; BELCHIOR, G. P. N. Resíduos Sólidos e Políticas Públicas: diálogos entre universidades, poder público e empresa. - Florianópolis: Insular, 2014.

MAIELLO, A.; BRITTO, A. L. N. de P.; VALLE, T. F. Implementação da Política Nacional de Resíduos Sólidos. Revista de Administração Pública, v. 52, n. 1, p. 24-51, 2018.

MANKIW, N. G. Externalidades. In: MANKIW, N. G. Introdução à Economia. São Paulo: Campos, 2001. cap. 10. p.203-22.

MAYER, A. Education and the environment: an international study, International Journal of Sustainable Development \& World Ecology, v. 20, n. 6, p. 512-519, 2013.

MCGREAVY, B.; RANDALL, S.; QUIRING, T.; HATHAWAY, C.; HILLYER, G. Enhancing adaptive capacities in coastal communities through engaged communication research: Insights from a statewide study of shellfish comanagement. Ocean and Coastal Management, v. 163, n. August 2017, p. 240-253, 2018.

MORAR, F.; BUCUR, B. Raising Awareness on Waste Generation and Collection. Procedia Engineering, v. 181, p. 452-458, 2017. 
MOREIRA, D. A.; ZAIDAN, S. R.; KOZLOWSKI, H. L.; ARRAES, R. V. Responsabilidade ambiental pós-consumo à luz do princípio do poluidorpagador: uma análise do nível de implementação da responsabilidade compartilhada pelo ciclo de vida dos produtos prevista na Política Nacional de Resíduos Sólidos. Revista de Direito da Cidade, v. 8, n. 4, p. 1442- 1467. 2016.

MOURA, E. F.; ALBUQUERQUE, W. G.; ALVES, M. F. A.; LUCENA, K. P. Análise comparativa da concepção ambiental de discentes matriculados em escolas públicas e privadas da cidade de Pombal - PB. Revista Verde de Agroecologia e Desenvolvimento Sustentável, v. 9, n. 4, p. 173-180, outdez, 2014.

MURAKAMI, F.; SULZBACH, A.; PEREIRA, G. M.; BORCHARDT, M.; SELLITO, M. A. How the Brazilian government can use public policies to induce recycling and still save money? Journal of Cleaner Production, v. 96, p. 94101, jun. 2015.

OLIVEIRA, F. A. G. A Educação Ambiental Como Meio Para a Sustentabilidade. Revbea, v. 11, n. 5, p. 39-52, 2016.

OECD - Organisation for Economic Co-operation and Development. The Polluter-Pays Principle: OECD Analyses and Recommendations. Paris: OCDE, 1992. Disponível em: <http://www.oecd.org/officialdocuments/publicdis playdocumentpdf/?cote=OCDE/GD(92)81\&docLanguage $=\mathrm{En}>$. Acesso em: 9 maio 2018.

PANDIS, N. The chi-square test. American Journal of Orthodontics and Dentofacial Orthopedics, v. 150, n. 5, p. 898-899, 2016.

PETHECHUST, E. R. B.; CASIMIRO, L. M. S. M. de. O direito à cidade: eficiência da Política Nacional de Resíduos Sólidos à luz da análise econômica do direito. Revista de Direito da Cidade, v. 8, n. 1. p. 294-307. 2016.

PRODANOV, C. C.; FREITAS, E. C. Metodologia do Trabalho Científico: Métodos e Técnicas da Pesquisa e do Trabalho Acadêmico. 2 ed. Novo Hamburgo: Universidade Feevale, 2013.

$\mathrm{R}$ Core Team. R: A language and environment for statistical computing. $\mathrm{R}$ Foundation for Statistical Computing, Vienna, Austria. Disponível em $<$ https://www.R-project.org/>. Acesso em: 2 junho 2018.

RADA, E. C.; BRESCIANI, C.; GIRELLI, E.; RAGAZZI, M.; SCHIAVON, M.; TORRETTA, V. Analysis and measures to improve waste management in schools. Sustainability (Switzerland), v. 8, n. 9, p. 1-12, 2016.

REIGOTA, M. O que é Educação Ambiental? 1a ed. E-book. Brasiliense, 2017.

REIS, D.; FRIEDE, R.; LOPES, F. H. P. Política nacional dos resíduos sólidos (Lei no 12.305/2010) e Educação Ambiental. Revista Interdisciplinar de Direito, v. 14, n. 1, p. 99-111, jan./jun. 2017. 
ROSA, M. A.; CARNIATTO, I.; COELHO, W. A. Environmental Education and Public Policy: limits and possibilities of practice and management. Ambiência, v. 13, p. 123-141, 2017.

SALTER, Z.; VENVILLE, G.; LONGNECKER, N. An Australian story: School sustainability education in the lucky country. Australian Journal of Environmental Education, v. 27, n. 1, p. 149-159, 2011.

SANTOS, M. C. D. M. A responsabilidade compartilhada na Política Nacional de Resíduos Sólidos: uma análise da eficácia das disposições relativas ao consumidor. Revista Direito Ambiental e sociedade, v. 5, n. 1, p. 248-276, 2015.

SEVERINO, A. J. Metodologia do trabalho científico. [s.l.]: Cortez Editora, 2017.

SILVA, C. L. Proposal of a dynamic model to evaluate public policies for the circular economy: Scenarios applied to the municipality of Curitiba. Waste Management, v. 78, p. 456-466, ago. 2018.

SILVA, E. A.; OLIVEIRA, C. A. M.; CUNHA, R. R. C. A.; SOARES, R. V. S.; TEIXEIRA, V. D.; GUENTHER, M. Educação Ambiental voltada para a reutilização e reciclagem dos resíduos sólidos no ambiente escolar: um estudo de caso no ensino fundamental em Recife (PE). Revista Brasileira de Educação Ambiental (RevBEA), v. 9, n. 2, p. 412-423, 2014.

SOUSA, C. A. F.; ALVES, A. F.; ANDRADE, T. M.; NICODEMO, S. C. T. S.; VITORINO, G. O. A percepção ambiental de atores sociais de escolas públicas e privadas, em um bairro de João Pessoa (PB). Revista Brasileira de Educação Ambiental (RevBEA), v. 12, n. 4, p. 180-191, 2017.

TABOADA, C. P. El Principio "Quien Contamina Paga" Y El Principio de Capacidad Económica. In: TÔRRES, H. T. Direito Tributário Ambiental. São Paulo: Malheiros, 2005

TAVARES, P. A.; BELTRÃO, N. E. S.; PIMENTA, L. B. Opções Didáticas Para O Ambiental No Ensino Básico De Tempo Integral. Revista Brasileira de Educação Ambiental (RevBEA), v. 12, n. 4, p. 25-43, 2017.

TREMBLAY, C. Towards inclusive waste management: participatory video as a communication tool. Proceedings of the Institution of Civil Engineers Waste and Resource Management, v. 166, n. 4, p. 177-186, 2013.

ZORPAS, A. A.; VOUKKALI, I.; LOIZIA, P. Effectiveness of waste prevention program in primary students' schools. Environmental Science and Pollution Research, v. 24, n. 16, p. 14304-14311, 2017. 